abscess. The kidney was not involved by the malignant process. Histology later revealed that the uterine mass was a mixed mesodermal sarcoma with a pattern of fibrosarcoma, chondrosarcoma, and in places osteogenic sarcoma. Review of the segment of colon removed at operation showed that this was in fact invaded from without by secondaries from the primary uterine tumour.

\section{Discussion}

Spontaneous rupture of the renal pelvis is rare and is most commonly caused by a stone impacted at the pelvi-ureteric junction (Mathé, 1932). Cases have been reported of rupture due to secondary deposits in the ureter (Ferguson, 1944), and to pregnancy (Jeppeson, 1961). Pyelonephritis may also lead to spontaneous rupture (Mathé, 1932; Jeppeson, 1961 ; Fine \& Vermooton, 1960). Involvement of the ureters by carcinoma of the cervix is well known, but in a recent survey no cases of rupture of the renal pelvis were described (Mallik, 1962).

It seems likely that the primary tumour in our patient caused early obstruction of the ureter, with resultant pyelitis which led to spontaneous rupture of the pelvis of the kidney, the basic lesion not being apparent at the first admission. Mixed mesodermal tumour of the uterus is rare (Pickles, 1957) and usually presents with post-menopausal bleeding or foul vaginal discharge. Our patient had no such symptoms on her first admission and a mass in the pelvis could not be felt until her second admission to hospital suggesting that the tumour was growing rapidly. This would be in keeping with the known bad prognosis of these tumours.

\section{Summary}

A case of spontaneous rupture of the kidney is described where the obstructing lesion was at the lower end of the ureter and was due to secondary spread from the rare uterine tumour, mixed mesodermal sarcoma. This case is of interest as both conditions are rare and we have been unable to find any report of a case in which the kidney has ruptured as a result of lower ureteric obstruction.

\section{Acknowledgment}

We would like to thank Mr G. E. Moloney for permission to publish details of this patient who was admitted under his care, and for his help in the preparation of this paper.

\section{References}

FERGUSSON, J.D. (1944) Ureteral stricture with perinephric urinary extravasation caused by metastases from a silent carcinoma of the stomach. Brit. J. Surg. 31, 283.

Fine, M.G. \& Vermooten, V. (1960) Spontaneous extravasation associated with excretory urography. J. Urol. 84, 409.

JEPPESEN, F.B. (1961) Spontaneous rupture of the kidney. J. Urol. 86, 489.

Mallik, M.K. Basu (1962) A study of the renal tract in cases of recurrence of carcinoma of the cervix, with special reference to its diagnostic value. Brit. J. Urol. 34, 181.

MATHE, C.P. (1932) Spontaneous rupture of the kidney. Urol. Cutan. Rev. 36, 605.

Pickles, B.G. (1957) Mesodermal mixed tumour of the uterus. Case report and review of the literature. J. Obstet. Gynec. Brit. Emp. 64, 700.

Shaw, R.E. (1957) Spontaneous rupture of the kidney. Brit.J. Surg. 45, 68.

\title{
Internal herniation through the transverse mesocolon complicated by volvulus
}

\author{
A rare complication of a rare hernia \\ R. P. Rosswick* \\ M.Sc.(Illinois), M.B., F.R.C.S. \\ Department of Surgery, St George's Hospital, London, S.W.1
}

Herniation into the lesser sac through a deficiency in the mesentery of the transverse colon is known as a mesocolic hernia even though usually there is no true peritoneal sac. The condition was first described by Pringle in 1919, and Menegaux (1934) in a classical review of the subject reviewed

\footnotetext{
*Present address: Royal Hampshire County Hospital, Winchester, Hants.
}

fifty-one cases, only five of them having a peritoneal sac. More recent reviews by Smith (1945), Gallagher (1949) and Stewart (1962) have added single cases. The purpose of this communication is to draw attention to the condition again, and to record a complication of this condition never before reported in a patient older than any other yet reported. 


\section{Case report}

A woman, aged 79 , was admitted as an emergency, having been found collapsed at home. When admitted, she was almost moribund, pulse 120/ min, BP $80 / 0 \mathrm{mmHg}$ but it was obvious that her collapse was due to an abdominal catastrophe, the presumptive diagnosis being a mesenteric vascular accident. Vigorous resuscitation made it possible to consider laparotomy.

Laparotomy through a right paramedian incision revealed gangrenous small intestine visible through the greater omentum and further exploration showed that almost all the ileum had herniated through a triangular hole in the mesocolon to the left of the ligament of Treitz and $10 \mathrm{~cm}$ to the left of the inferior mesenteric vessel, the edge of which was rounded and thickened. Through it the whole of the ileum had herniated into the lesser sac. It proved possible to reduce the contents of the hernia en masse; the gangrenous appearance was then found to be due to a spontaneous volvulus of part of the ileum. This was reduced, but $3 \mathrm{ft}$ had to be resected. The edges of the defect were sutured together as far as was possible and the abdomen closed.

Recovery was complicated by mild congestive failure, but the patient eventually made a complete recovery.

She had undergone right nephrectomy, ovarian cystectomy and appendicectomy many years before. She had had indigestion for years, and a barium meal taken some months before the present episode had shown an 'hour-glass' deformity of the stomach. After operation, a further series of barium meals showed a lesser-curve gastric ulcer, which later healed. Review of all the films failed to show any evidence of small intestine behind the stomach. She had had no symptoms which suggested previous episodes of obstruction.

\section{Discussion}

Mesocolic hernia is not usually diagnosed before laparotomy undertaken for abdominal pain or obstruction. Usually, the obstructive point is the edge of the defect and in enlarging the opening to permit reduction of the contents care has to be taken to avoid damage to the inferior mesenteric vessels which may lie close to either edge of the defect. However, in this case, the opening was large and there were no adhesions within the lesser sac.

In other cases symptoms have been due to the small intestine escaping from the lesser sac through the foramen of Winslow, with volvulus occurring in the greater sac, or through another hole in the lesser omentum causing a volvulus of the stomach.

In many cases symptoms are thought to be due to peptic ulcer which has been found in association with the majority of cases. This relationship has been commented on by several authors, Menegaux (1934) and Tanner (1945) considering this to be a causal one: but, as Barret (1935) has observed, peritoneal inflammation causes thickening rather than thinning of the mesentery, thus making the formation of 'holes' less likely. In the present case the edges were thickened as if the defect had been present for a considerable time, similar to the thickening at the neck of a long-standing hernia.

\section{Summary}

A further case of mesocolic hernia, with a previously unrecorded complication, is reported. The association with peptic ulceration is commented on.

\section{Acknowledgments}

It is a pleasure to thank $\mathrm{Mr} \mathrm{K}$. W. Wilkinson for permission to report this case and Professor Bryan N. Brooke for his advice in the preparation of this report.

\section{References}

BARRETT, N.R. (1935) Bilocular stomach due to hernia of the small bowel through the traverse mesocolon. Brit. $J$. Surg. 23, 469.

Gallagher, H.W. (1949) Herniation through traverse mesocolon. Brit. J. Surg. 26, 300.

MenegauX, G. (1934) Les hernies transmesocoliques. $J$. Chir. Med. 43, 321.

Pringle, J. (1919) Hernia across the lesser sac of the peritoneum. Glasgow med. J. 41, 129.

Smith, R. (1945) Hernia of the ileum through a hole in the transverse mesocolon. Brit. J. Surg. 33, 187.

StewART, J.O.R. (1962) Lesser sac hernia. Brit. J. Surg. 50, 321.

TANner, N.C. (1945) Hernia traversing the lesser sac. Brit. J. Surg. 33, 184. 